\title{
Polyhydroxyalkanoates (PHAs) from dairy wastewater effluent: bacterial accumulation, structural characterization and physical properties
}

\section{Giorgia Pagliano}

Universita degli Studi di Napoli Federico II

\section{Wanda Gugliucci}

Universita degli Studi di Napoli Federico II

\section{Elena Torrieri}

Universita degli Studi di Napoli Federico II

\section{Alessandro Piccolo}

Universita degli Studi di Napoli Federico II

\section{Silvana Cangemi}

Universita degli Studi di Napoli Federico II

\section{Fabio A Di Giuseppe}

Universita degli Studi di Napoli Federico II

\section{Alessandro Robertiello}

Universita degli Studi di Napoli Federico II

\section{Vincenza Faraco}

Universita degli Studi di Napoli Federico II

Olimpia Pepe ( $\nabla$ olipepe@unina.it )

University of Naples Federico II

\section{Valeria Ventorino}

Universita degli Studi di Napoli Federico II

\section{Research}

Keywords: biodigestate, volatile fatty acids, Cupriavidus necator, poly- $\beta$-hydroxybutyrate, biopolymer properties

Posted Date: May 27th, 2020

DOI: https://doi.org/10.21203/rs.3.rs-30604/v1

License: (c) (i) This work is licensed under a Creative Commons Attribution 4.0 International License. 

1 Polyhydroxyalkanoates (PHAs) from dairy wastewater effluent: bacterial accumulation,

2 structural characterization and physical properties

3

4 Giorgia Pagliano ${ }^{a, 1}$, Wanda Gugliucci ${ }^{a, 1}$, Elena Torrieria, Alessandro Piccolo ${ }^{a}$, Silvana Cangemi, 5 Fabio Angelo Di Giuseppe ${ }^{a}$, Alessandro Robertiello ${ }^{a}$, Vincenza Faraco ${ }^{b}$, Olimpia Pepe ${ }^{a} *$, Valeria 6 Ventorino $^{\mathrm{a}}$

$7{ }^{\text {a }}$ Department of Agricultural Sciences, University of Naples Federico II, Portici (Naples), Italy

$8 \quad{ }^{\mathrm{b}}$ Department of Chemical Sciences, University of Naples Federico II, Naples, Italy

$9 *$ Corresponding author at: University of Naples Federico II, Department of Agricultural Sciences, via 10 Università 100, 80055 N, Portici (Naples), Italy. E-mail address: olipepe@ unina.it (O.Pepe).

$11{ }^{1}$ These authors contributed equally to this work.

\section{Abstract}

14 Background: to establish bioplastics the real alternative to conventional plastics, high production costs have to be constrained by using different kind of wastewater streams as organic substrate and novel microbial strains as accumulating bacteria with high performance. Volatile fatty acids (VFAs) from effluent of dairy wastewater biodigestion represent a new and cheap feedstock used in this study for biopolymers production through microbial processes.

19 Results: Cupriavidus necator DSM 13513 was particularly able to accumulate PHAs operating in fedbatch mode by limiting oxygen level together with intermittent feeding of carbon source with the maximum PHB accumulated in $48 \mathrm{~h}$ without compromising the microbial growth. The complex VFA mixture from digestate did not influence the PHA homopolymer accumulation. In fact, structural characterization by NMR analysis revealed the 3-hydroxybutirrate synthesis (PHB) by C. necator DSM 
DSM 13513 cells grown on VFA from digested dairy waste effluent, presented good thermic properties and low affinity to water.

Conclusions: overall results making the digested dairy waste effluent suitable for PHB production for specific bio-based industrial applications.

Keywords: biodigestate, volatile fatty acids, Cupriavidus necator, poly- $\beta$-hydroxybutyrate, biopolymer properties

\section{Background}

One of the key challenges of this century in the environmental field is to replace, progressively, plastics deriving from the fossil fuels with bio-based, biodegradable and compostable plastics deriving from nofood renewable sources [1]. The European Commission is promoting "Circular Economy Action Plan" to replace conventional plastic generally utilized for single-use products, with a bioplastic by 2021 (EURLex-52018PC0340). In order to establish bioplastics as a real alternative to conventional plastics, high production costs have to be constrained by using different kind of wastewater streams as organic substrate and novel microbial strains as accumulating bacteria with high performance. This aim could be achieved by eco-designing sustainable biopolymers production through microbial bio-based process [2,3]. Among biopolymers, microbial polyesters known as polyhydroxyalkanoates (PHAs) are biodegradable plastics synthesized by different bacteria from a range of substrates including sugars and fatty acids [4]. Volatile fatty acids (VFAs) such as acetic, propionic, butyric, etc., are potentially renewable carbon sources [5] that could be used for biogas production [6] generation of electricity [7] and synthesis of PHAs [8]. However, the larger quantity of VFAs is in the effluents of the acidogenic bio- $\mathrm{H}_{2}$ that represents an interesting feedstock for PHA production process and an opportunity to enhance the treatment of those effluents [9]. In this context, in the last decades, many studies focused the attention on energy source 
such as hydrogen produced from dairy wastes [10,6] showing the options to valorize this effluent in the chemicals industry or by other biological system for energy recovery (e.g. methane). In fact, an

51 interesting integrated system can be designed to combine energy source (mainly hydrogen) and

52 biopolymers production (PHAs) utilizing the acid rich wastewater stream [4]. For these reasons, also the 53 effluent from acidogenic digestion of dairy wastes is an inexpensive acid - rich wastewater stream for PHA production [11]. In particular, whey and buttermilk are suitable by-products that can be submitted to hydrolysis-acidification step under anaerobic condition to produce hydrogen and VFAs. In fact, this wastewater stream manly includes VFAs, lactic acid, alcohols and the residues which are un-hydrolyzed [9]. The resulted VFAs with lower carbons are the main precursors for the PHAs production by many microbial species.

A well-known PHA accumulating microbial species is Cupriavidus (C.) necator, synonym Wautersia eutropha and Alcaligenes eutrophus, formerly classified as Ralstonia eutropha [12]. Gram-negative bacterial strains belonging to this species are able to accumulate higher yield of PHAs from VFA as intracellular carbon and energy reserve granules, depending on the strain and operating mode [13]. Indeed, PHAs and their copolymers are classified based on the length of alkyl side chain present in the PHAs that is correlated to the substrate specificity of PHAs synthases. Typically, $C$. necator produce short chain (C3-C5) hydroxyalkanoic acids (PHAsCL) which has an alkyl side chain such as $\mathrm{P}(3 \mathrm{HB})$, $\mathrm{P}(3 \mathrm{HV}), \mathrm{P}(4 \mathrm{HB})$ and co-polymer of $\mathrm{P}(3 \mathrm{HB}-\mathrm{co}-3 \mathrm{HV})[14]$. Therefore, it is essential to determine the chemical composition to evaluate their potential use for industrial purpose. Gas Chromatography-Mass Spectrometry (GC-MS) as well Nuclear Magnetic Resonance (NMR) are among the most widely used analysis for the chemical characterization of PHA structure [15] since their coupled use allow to obtain a careful and unambiguous molecular description.

71 PHAs represents a heterogeneous family of bio-based (co-)polyesters constituted by more than 150 different monomers to give materials with extremely different properties not always fully competitive 
73 compared to conventional thermoplastics [16]. Although PHAs can show poor physical properties due 74 to secondary crystallization and slow nucleation rate, they have physical properties comparable to 75 petroleum-based thermoplastics. In particular, poli- $\beta$-idrossibutirrato (PHB) exhibits remarkable 76 physical properties, comparable to polypropylene (PP) and polyethylene (PE). The stereo-chemical 77 regularity of their structure leads to a highly crystallized homopolymer (crystallinity up to $70 \%$ ) 78 contributing to its excellent physical properties [17]. Kinetic data obtained from thermogravimetric 79 (TGA) measurements are very useful for understanding thermal degradation processes. Many studies have revealed that the degradation occurs rapidly near the melting point mainly through a random chain 81 scission process based on typical structures of pyrolysis products, i.e. crotonic acid and oligomers with 82 a crotonate end group [18,19]. On the other hand, they have also shown that the parameters of melt 83 processing must be optimized in order to avoid or restrict this phenomenon that reduces the processing 84 window.

85 Hence, the PHA production chain through biological process involves high biotechnological 86 performance of bacterial strains, low cost feedstock selection, fermentation technology as well as 87 downstream technologies [20]. The present study analyzed many aspects of the sustainable production 88 of bio-based plastic film composed by PHAs using organic acids obtained from the first step of 89 biodigestion of dairy waste. Different strains belonging to $C$. necator species were assayed to study their 90 ability to accumulate PHAs growing on organic acids from dairy waste biodigestion effluent as well as 91 synthetic mixture of pure acids as growth media. Their biotechnological performances were compared 92 by detecting and monitoring cell growth, PHAs formation and quantification. In addition, the PHA 93 monomeric composition was qualitatively analyzed by GC/MS and structurally characterized by NMR.

94 The thermal degradation behaviors of PHA samples have been characterized under isothermal conditions. 95 Moreover, to understand the interaction of PHA with water, the water absorption kinetic has been studied 96 at $40^{\circ} \mathrm{C}$. 


\section{Results and Discussion}

\section{Ability of $C$. necator strains to growth in medium containing VFAs}

100 A preliminary screening of the strains $C$. necator DSM 13513, DSM 531 and DSM 428 was performed 101 on the basis of their capacity to grow in presence of a mixture of VFAs. In the Figure 1 were reported 102 the growth curves of the three strains in LB with VFA synthetic $_{\text {(Figure 1a), in LB with VFAextracted (Figure }}$ 103 1b) and LB (control; Figure 1c). All C. necator strains showed an enhanced growth by an excess of 104 carbon source due to the organic acid addition $\left(\right.$ VFA $\left._{\text {synthetic }}\right)$ in the culture medium. In particular, $C$. 105 necator DSM 13513 showed the highest growth, achieving 1.97 O.D.600nm at $40 \mathrm{~h}$ in the presence of 106 VFA $_{\text {synthetic }}$ (Figure 1a) compared to the control assay (0.90 O.D.600nm; Figure 1c). These results 107 demonstrated that these bacterial strains were well adapted to the acidogenic nutritional conditions due 108 to the VFA mixture addition. The strain C. necator DSM 13513 showed the best growth (0.97 O.D.600nm;

109 Figure 2b) also in presence of VFAextracted with a trend similar to that detected in LB broth (control tests 110 without VFA; Figure 1c). Based on the chemical characterization of the VFA extracted mixture, the main 111 difference with the VFA $\mathrm{Vynthetic}_{\text {was }}$ the presence of the ethanol $\left(20.24 \pm 0.52 \mathrm{~g} \mathrm{~L}^{-1}\right.$ of ethanol) that did not 112 affect the growth of the bacterial strains as showed by comparison with control test without VFA (Figure $1131 \mathrm{~b}$ and $1 \mathrm{c})$. In fact, according to Obruca et al. [21] the exposition of $C$. necator to ethanol can enhance 114 the PHB production without inhibit the microbial growth. Indeed, at low concentration organic acid 115 mixture can be effectively utilized by $C$. necator as substrate for bacterial growth, although organic acid 116 mixture could be toxic to cells [22].

117 This preliminary screening allowed to select the strain C. necator DSM 13513 for further investigations 118 on PHA producing from VFA. 
121 On the basis of the previous results, batch culture experiments (600 mL) with C. necator DSM 13513 122 and media containing $\mathrm{VFA}_{\text {synthetic }}$ or $\mathrm{VFA}_{\text {extracted }}$ were conducted to evaluate the PHAs synthesis. After $12324 \mathrm{~h}$ of incubation at $30{ }^{\circ} \mathrm{C}$ at the up Log phase of growth, the PHB achieved $0.31 \%$ (Figure $2 \mathrm{a}$ ) in the 124 medium containing VFA synthetic, $_{12}$ folds higher than that accumulated in the test control (optimal medium 125 without $\left.\mathrm{VFA}_{\text {synthetic }}\right)$ at same time $(0.025 \%)$ (Figure $\left.2 \mathrm{c}\right)$. In fact, various bacteria are able to utilize acetic, 126 propionic and formic acid as substrate for PHA synthesis [23]. Among them, C. necator species is known 127 to be one of the best PHB accumulating bacteria [24], even if the biotechnological performances are 128 strain dependent. This was also demonstrated in this research since C. necator DSM 13513 was selected 129 as the best strain to accumulate PHB from fatty acids effluent of anaerobic process fed with dairy wastes. 130 After 24 h of growth also the cellular concentration of $C$. necator DSM 13513 was higher in the batch 131 cultures with $\mathrm{VFA}_{\text {synthetic }}\left(9.38 \log \mathrm{CFU} \mathrm{mL} \mathrm{m}^{-1}\right.$; Figure $\left.2 \mathrm{a}\right)$ with respect to the control medium (8.70 $\log$ $132 \mathrm{CFU} \mathrm{mL} \mathrm{m}^{-1}$; Figure 2c). The $\mathrm{VFA}_{\text {synthetic }}$ addition prolonged the exponential growth phase by delaying the 133 start of the stationary phase where a decrease in the percentage of PHB was observed. This result was 134 probably due to a consumption of PHB accumulated in the cells as energy reserve for lack of carbon 135 source. Moreover, several microbial strains show PHB accumulation until the stationary phase as reported by Bhatia et al. [25] that studied recombinant Escherichia coli strain SKB99.

137 In presence of $\mathrm{VFA}_{\text {extracted, }}$ the strain $C$. necator DSM 13513 showed a particular trend prolonging the 138 Log phase after $24 \mathrm{~h}$ of incubation ranging a microbial count from $7.37 \log \mathrm{CFU} \mathrm{mL} \mathrm{mL}^{-1}$ at $24 \mathrm{~h}$ to $9.03 \log$ $139 \mathrm{CFU} \mathrm{mL} \mathrm{m}^{-1}$ at $48 \mathrm{~h}$ (Figure $2 \mathrm{~b}$ ). This behavior was related to an increase in the PHB production achieving 140 a value $0.2 \%$ of PHB after $24 \mathrm{~h}$ of incubation with a significant increment of PHB until $0.48 \%$ at $48 \mathrm{~h}$ 141 (Figure 2b). Even if, C. necator DSM 13513 showed a slower growth rate, PHB synthesis was stimulated 142 by the presence of $\mathrm{VFA}_{\text {extracted }}$ in the medium. Interestingly, the trend of the curve of PHB did not reach 143 the plateau after 48 hours demonstrating the opportunity of extending accumulation time in the cells. 144 However, at $48 \mathrm{~h}$ the same microbial concentration was observed in all experimental conditions. 
145 As previous described, the presence of ethanol in the $\mathrm{VFA}_{\text {extracted }}$ did not influence the microbial growth 146 but Obruca et al. [21] demonstrated that it could increase the PHB yield about 30\%. Ethanol is considered 147 a precursor of PHA, in particular of HV [26] or HB [27], but there is no clear indication of the microbial 148 pathway.

149 PHAs accumulation in the media with and without VFAs mixtures was observed under fluorescence 150 microscope as shown in the Figure 3. An increase of fluorescence was observed after 24 or $48 \mathrm{~h}$ of 151 incubation, in correspondence with the maximum of PHB accumulation in the media containing $152 V_{\text {VFA }}$ synthetic or VFA extracted, respectively.

\section{PHA production fed-batch fermentation experiments}

\section{Set up of fermentation conditions}

156 On the basis of the batch culture results, to analyze the relationship between carbon source, oxygen 157 availability, and polymer accumulation, fed-batch fermentation experiments in LB supplemented with $158 \mathrm{VFA}_{\text {synthetic }}$ were carried out testing three different aeration conditions. In no aeration condition, the PHB production reached a value of $0.81 \%$ after $48 \mathrm{~h}$ (Table 1). Jackson et al. [28] reported that oxygen 160 limitation increases the NADH/NAD ratio and high concentration of NADH inhibits citrate synthase and 161 isocitrate dehydrogenase, blocking the TCA cycle. The accumulation of acetyl-CoA triggers the PHB 162 synthesis, during which the PHB assumes the role of an alternative electron acceptor. Under the steady 163 aeration condition, the PHB production was lower $(0.60 \%$ at $48 \mathrm{~h}$, Table 1$)$ than that produced without 164 aeration. It was probably due to a PHB consumption related to the fermentative condition operating in 165 fed-batch mode. When the fermentation was performed applying air sparging for $12 \mathrm{~h}$ followed by no 166 
169 lead to significant changes in the metabolism of $C$. necator cultures. These changes vary when different 170 acid mixture and substrate are used affecting the synthesis of PHB in several ways [29]. The strategy for

171 efficient production of PHB by limiting oxygen level together with intermittent feeding of carbon source 172 was investigated by Nath et al. [30] in a fed batch culture of Methylobacterium sp. They reported an 173 increase in PHB production by 0.8 -fold by limiting the oxygen levels in the fermenter. Instead, in this 174 study, a PHB production two-fold higher than aeration condition was achieved by limiting aeration cycle 175 at $12 \mathrm{~h}$ in fed batch mode. Although there are many studies focused on the behavior of many microbial 176 strains under different aeration condition [30,31,32], the role of oxygen is not already clear, since in some 177 case allows an enhancement in PHA synthesis, in other cases a negative influence was observed $178[30,33,34]$. On the other hands results obtained demonstrate that the biotechnological performances of 179 the bacterial strains in terms of rate of production, was strongly influenced by composition of the growth 180 medium as well as by the specific scale up conditions of the bio-based process.

\section{PHA production in fed-batch fermentation with VFAextracted}

183 On the basis of results obtained in the fermentation experiments with $\mathrm{VFA}_{\text {synthetic }}$, air sparging for $12 \mathrm{~h}$ 184 followed by no aeration was chosen to evaluate the accumulation of PHB with VFA extracted. In this case, 185 the culture accumulated a PHB percentage $(0.52 \%$ at $48 \mathrm{~h})$ lower that previous experiment operating 186 under the same aerating condition (Table 1). The main difference among these experiments is the carbon 187 source $\left(\mathrm{VFA}_{\text {synthetic }}\right.$ and $\left.\mathrm{VFA}_{\text {extracted}}\right)$. In fact, the use of organic acid extracted from digestate could 188 promote the PHB accumulation instead of microbial growth as also reported by Passanha et al. [35]. On 189 the contrary, the VFA extracted mixture used in this study stimulated the microbial grow achieving 9.59 190 Log CFU mL $\mathrm{m}^{-1}$, value higher than previous fermentation tests. Moreover, the complex nature of VFA 191 mixture extracted from digestate may have several nutrients and compounds uptaken to the system in 
192 every feeding pulse creating an in balance between nutrient and carbon sources. In this way, the 193 nutritional stress conditions necessary for the PHB accumulation were lacking.

Monomer unit of the PHAs polymer from $\mathrm{VFA} A_{\text {synthetic }}$ and $\mathrm{VFA} A_{\text {extracted }}$

196

197

198

199

200

201

202

203

204

205

206

207

208

209

210

211

212

In the Figure 4a is shown the highest peak from the GC analysis of PHAs synthetized by $C$. necator DSM

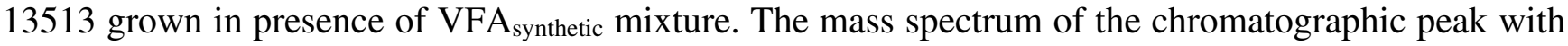
retention time about 4.1 min corresponding to the main monomer unit of polymer, revealed the presence of 3-hydroxybutyrate according to the mass spectral library from the NIST database. The other peaks depend from the solvents used for methanolysis. Similar result was obtained in the presence of $\mathrm{VFA}_{\text {extracted }}$ (Figure 4b). In fact, it has been shown that $C$. necator species predominantly accumulates the homopolymer PHB by $\beta$-oxidation pathway [36] by using butyric acid, present in both VFA mixtures, that it is well known as the main PHB precursor [37].

The mass spectra of both samples are dominated by the fragment at $\mathrm{m} / \mathrm{z}=74$, due to the Mc Lafferty rearrangement of the methyl ester; whereas, the fragment at $\mathrm{m} / \mathrm{z}=103$ is due to the break between Carbon 3 and Carbon 4 of the molecule. The loss of the $\mathrm{CH}_{3} \mathrm{OH}$ group from the fragment at $\mathrm{m} / \mathrm{z}=103$ could instead explain the presence of the intense signal at $\mathrm{m} / \mathrm{z}=71$. The signal of the molecular ion shows low abundance probably due to the high energy not absorbed by the molecule following the electronic impact.

\section{Structural characterization by NMR analysis}

The Figure 5 showed ${ }^{1} \mathrm{H}$ and ${ }^{13} \mathrm{C}$ NMR spectra of PHAs synthetized by $C$. necator DSM 13513 grown in presence of $\mathrm{VFA}_{\text {synthetic }}$ mixture (A), and VFA extracted (B) compared with the Poly(R)-3-hydroxybutyric acid standard. In the ${ }^{1} \mathrm{H}$ spectra signals (Figure 5a) were detected at a chemical shift of $\delta=5.2,2.5,1.2$, which corresponded to a $-\mathrm{CH}$ multiplet, $-\mathrm{CH}_{2}$ multiplet, $-\mathrm{CH}_{3}$ doublet, respectively. The doublet at $\delta=$ 1.2 was attributed to the methyl protons (side chain of 3-hydroxybutyric acid). The multiplet at $\delta=2.5$ 
$216 \mathrm{ppm}$ was due to the diastereotopic protons at position 2 of the chemical structure, finally the quartet at $\delta$ $217=5.2 \mathrm{ppm}$ was attributed to the proton close to the carboxyl oxygen $(-\mathrm{CH})$. In the ${ }^{13} \mathrm{C}$ NMR spectra 218 (Figure 5b) were evidenced four signals at a chemical shift of $\delta=19.7 \mathrm{ppm}, 40.7 \mathrm{ppm}, 67.6 \mathrm{ppm}$ e 169.1 219 ppm, which were attributed, respectively, to methyl carbon (side chain of 3-hydroxybutyrate), methylene 220 carbon (backbone of 3-hydroxybutyrate), methane carbon (chiral center of 3-hydroxybutyrate) and 221 carbonyl carbon. At last, the NMR spectra indicate that the analyzed samples contained poly(R)-3222 hydroxybutyric acid.

\section{Characteristics of the bioplastic film}

\section{Thermal stability}

226 The Figure 6 shows the bioplastic disk obtained from the microbial cells of $C$. necator DSM 13513 grew on VFA extracted from digested dairy wastes effluent. The TGA mass loss curve and the corresponding derivate curve (DTGA) obtained for the studied PHB is shown in Figure 7. The decomposition of PHAs showed mainly weight loss from $200^{\circ} \mathrm{C}$ to $250^{\circ} \mathrm{C}$ followed by a moderated weight loss up to $499{ }^{\circ} \mathrm{C}$ [38] . The extrapolated onset Temperature is $230.13{ }^{\circ} \mathrm{C}$. The DTG curve shows three well-defined degradation stages at $247{ }^{\circ} \mathrm{C}$, and two minor picks at $376{ }^{\circ} \mathrm{C}$ and $414{ }^{\circ} \mathrm{C}$, being the first one the main transition as it comprises ca. $60 \mathrm{wt} \%$. First peak indicates the point of greatest rate of change on the weight loss curve. As reported in literature, the PHAs degradation occurs according to a random chain scission reaction of ester linkage just above their melting temperature, resulting in a TG curve characterized by a one-step process [38,39]. Moreover, Herrera-Kao et al. [40] reported that although the degradation of PHB occurs in two stages, only in the former, carboxylic acids and ester moiety were detected being possible suggest that a random chain scission reaction takes place during thermal decomposition of this polymer. In the following degradation the crotonic acid and a variety of oligomers may be further deconstructed into 
240376 and $414{ }^{\circ} \mathrm{C}$ has also been reported by Follain et al. [42] for PHBV commercial pallet. They reported 241 that this additional degradation peak could be related to organic additives present in the commercial 242 samples. The degradation temperatures of the polymer were quite consistent with values reported in 243 literature for PHAs obtained by fermented sugar cane molasse $\left(251^{\circ} \mathrm{C}\right)$ [26], and slight lower than PHBV 244 at $4 \% \mathrm{HV}\left(265^{\circ} \mathrm{C}\right)$, and $\mathrm{PHB}$ at $0 \% \mathrm{HV}\left(275^{\circ} \mathrm{C}\right)[39]$.

\section{Water vapor sorption isotherm of the PHAs film}

247 The isotherm curves, representing the water concentration at the sorption equilibrium state as a function 248 of aw (\%) of the PHAs film are plotted in Figure 8. The maximum mass gain from film was below 20\%, 249 reflecting a medium affinity of biopolymer to water. The hydrophilic ester groups could be responsible 250 of water immobilization. A lower affinity to water was reported for PHAs, PLA or PCL film [42,43,44]. 251 The adsorption isotherm showed a sigmoidal curve that is typical for this type of biopolymer material. 252 Nevertheless, the sigmoidal shape of isotherms, as exhibited by the PHAs films, is obviously maintained 253 and corresponds to a type II isotherm in reference to Rogers' classification. Generally, in the literature, 254 a sigmoid profile conforms to multi-mode sorption divided into three contributions. In the region of aw 255 between 0.3 and 0.7 the water is absorbed at the multilayer; whereas at a $>0.75$ the water absorbed 256 corresponds to the condensation of water in the pores of the film. The casting method obviously favors

257 the entrance of water molecules into the films. During solvent evaporation in the casting method, the 258 polymer chains have retained enough motion levels (such as translation and rotation motions) to create 259 additional free volume, making the films less dense and more permeable.

260 The polymer structure is thus more easily opened and plasticized by water molecules, which behave as 261 mobility enhancers during water sorption. This causes the greater water sorption at high water activities 262 (aw > 0.75). A gradation of sorption isotherm profiles can be correlated to the degree of crystallization. 263 The BET molecular model of adsorption (fitted for $\mathrm{a}_{\mathrm{w}}$ 0.3-0.5) [45], the GAB model and the Peleg model 
264 were used to describe the water adsorption of films (Table 2). BET equation constants, which have a 265 thermodynamic base, has been used to analyze sample behavior and the interaction between the 266 components and water molecules. The monolayer moisture content $\left(\mathrm{x}_{\mathrm{m}}\right)$ of the PHAs was $0.022(\mathrm{mg}$ $267 \mathrm{mgd}_{\mathrm{m}}{ }^{-1}$ ), the $\mathrm{C}$ constant and RMSE were respectively 0.723 and 0.0001 (Table 2). According to the GAB 268 model, the $\mathrm{x}_{\mathrm{m}}$ value is $0.052\left(\mathrm{mg} \mathrm{mgd}_{\mathrm{m}}{ }^{-1}\right)$. This parameter was directly related to the number of 269 adsorption sites. The greater degree of intermolecular interaction probably decreased the number of free 270 sites for water molecules in the PHAs polymeric matrix [46]. The parameter $\mathrm{C}$ and $\mathrm{K}$ are related to the 271 quantity of water at the multilayer and to the energy needed to cut the interaction. For PHAs film are 272 respectively 0.003 and 0.79 (Table 2). The root mean squared error (RMSE) are 0.0036. For the peleg 273 model, $\mathrm{k}_{1}$ was 0.087 and $\mathrm{k}_{2}$ was $0.214\left(\mathrm{mg} \mathrm{mgd}_{\mathrm{m}}{ }^{-1}\right)$. The constant value $\mathrm{k}_{1}$ is related to mass transfer rate, 274 e.g., the lower the $\mathrm{k}_{1}$, the higher the initial water absorption rate [47]. The maximum water absorption 275 capacity is reported by $\mathrm{k}_{2}$ constant, the lower the $\mathrm{k}_{2}$, the higher the water absorption capacity. The RMSE 276 of Peleg model for PHA film are 0.0010. The Peleg and Bet equation gave similar good fits better than 277 GAB model, comparing RMSE value. Although the Bet equation gave marginally better than the Peleg and $\mathrm{GAB}$ equation, it was felt that this was more than onset for using a limited $\mathrm{a}_{\mathrm{w}}$ range (0.3-0.5).

279

280

\section{Conclusions}

281 Cupravidus necator DSM 13513 was able to synthetize PHAs using as carbon source the complex 282 organic acids mixture extracted from a dairy wastewater biodigestion effluent. Structural characterization revealed the accumulation of 3-hydroxybutyrate by $C$. necator DSM 13513 cells used to prepare 284 bioplastic disk that showed good thermic properties and poor affinity to water which are physical properties assimilating to conventional plastics. These results making the PHB obtained from digested dairy waste effluent suitable for specific bio-based industrial applications. 


\section{Material and Methods}

\section{Bacterial strains and culture condition}

290 The microorganisms used in this study were C. necator DSM 13513, C. necator DSM 428 and C. necator 291 DSM 531 (Leibniz Institute DSMZ-Germany).

292 C. necator strains were routinely grown on Luria-Bertani (LB) medium containing $10 \mathrm{~g} \mathrm{~L}^{-1}$ tryptone, 5 $293 \mathrm{~g} \mathrm{~L}^{-1}$ yeast extract, $10 \mathrm{~g} \mathrm{~L}^{-1} \mathrm{NaCl}$ (pH 7.0). For solid medium, bacteriological agar (Oxoid, Milan, Italy) 294 was added at a concentration of $15 \mathrm{~g} \mathrm{~L}^{-1}$ and was dissolved by heating the medium. Strains were grown 295 at $30{ }^{\circ} \mathrm{C}$ for $48-72 \mathrm{~h}$.

296 For PHA production, LB medium was supplemented with $2 \%(\mathrm{v} / \mathrm{v})$ of a mixture of synthetic VFA 297 (VFA $\left._{\text {synthetic }}\right)$ or extracted VFA (VFA extracted). VFA synthetic is a synthetic mixture of pure organic acids 298 (1:1:2 v/v of acetic, propionic and butyric acid, respectively) used to simulate, in terms of VFAs, a real 299 digestate effluent obtained in previous study [11]. VFA extracted derived from the digestate obtained by the 300 anaerobic process of a mixture of dairy waste from a mozzarella cheese factory. In this experiment, 301 biodigesters ( $5 \mathrm{~L}$ ) were filled with a mixture of cheese whey and buttermilk (ratio 2:1 v/v, respectively) 302 and inoculated with 5\% (w/v) of industrial animal manure pellets (Stalfert $\mathrm{N}_{2}$ - Organazoto Fertilizzanti 303 s.p.a, Pistoia, Italy) [11]. After 30 days, the digestate was collected and centrifuged at $4010 \times g$ for 10 304 min. The liquid fraction, containing the VFAs, was filtered (Minisart RC-25, $0.2 \mu \mathrm{L}$, Sartorius Stedim 305 Biotech, Goettingen, Germany) and characterized by high-performance liquid chromatography (HPLC, 306 refractive index detector 133; Gilson system; pump 307, column Metacarb 67 h from Varian with 0.4 $307 \mathrm{~mL} \mathrm{~min}^{-1}$ flow of $0.01 \mathrm{~N} \mathrm{H}_{2} \mathrm{SO}_{4}$ ) to determine its organic acids composition.

\section{Screening by bacterial growth with VFAs}

310 The bacterial strains were pre-inoculated dissolving a single colony into $9 \mathrm{~mL}$ of $\mathrm{LB}$ and incubated 311 overnight at $30{ }^{\circ} \mathrm{C}$. One $\mathrm{mL}$ of each culture (O.D.600nm 4.30;1\% v/v) was inoculated in test tubes 
312 containing $10 \mathrm{~mL}$ of $\mathrm{LB}$ medium with $2 \%(\mathrm{v} / \mathrm{v})$ of $\mathrm{VFA}_{\text {synthetic }}$ or $\mathrm{VFA}_{\text {extracted. }}$ From each tube, $220 \mu \mathrm{L}$ of 313 culture were dispensed in triplicate into a microtiter plate and growth curves were obtained by monitoring 314 the O.D.600nm in a Microplate Reader (BioTek ELx808) every 30 minutes for $72 \mathrm{~h}$ at $30^{\circ} \mathrm{C}$. LB without 315 VFA was used as control. All tests were performed in triplicate.

\section{PHA production in batch culture with synthetic and extracted VFA}

318 The preliminary screening for the evaluation of bacterial growth ability in LB supplemented with VFAs 319 allowed for the selection of the strain C. necator DSM 13513.

320 PHA production of the selected bacterial strain was assessed in batch culture with LB liquid medium $321(600 \mathrm{~mL})$ containing $2 \%(\mathrm{v} / \mathrm{v})$ of $\mathrm{VFA}_{\text {synthetic }}$ or $\mathrm{VFA}_{\text {extracted. The flasks were inoculated with } 1 \%(\mathrm{v} / \mathrm{v}) \text { of }}$ 322 bacterial cultures as above described and incubated at $30{ }^{\circ} \mathrm{C}$ for $48 \mathrm{~h}$ under continuously shaken at 200 $323 \mathrm{rpm}$. Flasks without VFA mixture were used as control. At initial time and after 3, 6, 9, 24, 30 and $48 \mathrm{~h}$, 324 samples were withdrawn to detect the accumulation of PHAs in the cells by staining $1 \mathrm{~mL}$ of cell 325 suspension with 1 drop of Nile Blue A [48]. Briefly, after incubation at $55{ }^{\circ} \mathrm{C}$ for $10 \mathrm{~min}$ and the pellet recovered by a new centrifugation was suspended in $0.9 \% \mathrm{NaCl}$ [48]. The presence of PHAs in the cells was detected by fluorescence microscope (Axiovert 200M, Zeiss, Göttingen, Germany). The microbial growth was also considered by measuring O.D.600nm (BioSpectrometer basic, Eppendorf, Milan, Italy) and enumerating ten-fold diluted cultures by spread plate method on LB solid medium $\left(\mathrm{CFU} \mathrm{mL}^{-}\right.$ $1)$.

333 For each sampling time, bacterial cultures growth in LB with $\mathrm{VFA}_{\text {synthetic }}$ or VFA extracted were freeze-dried 334 (Lyoquest -55, Telstar, Terrassa, Spain) for the PHAs extraction and quantification. 


\section{PHA extraction and quantification}

337 For the PHAs extraction from C. necator DSM 13513 cells, a modification of the method proposed by 338 Strazzullo et al. [49], was used. In detail, $100 \mathrm{~mL}$ of distilled water were added to dry pellet (1 up to $2 \mathrm{~g}$ ) 339 in order to obtain a complete dispersion of the cells by ultrasonication (Ultrasonic sonicator cleaning bath 340 HK3300, Falc, Treviglio, Italy) for 20 min. SDS solution (10\%; Serva, Heidelberg, Germany) was added 341 to digest the dispersed cells (wet cells weight:SDS ratio 1:1). After incubation for $1 \mathrm{~h}$ at $50{ }^{\circ} \mathrm{C}$ in a heater 342 (Mixing block MD-102, Bioer, Hangzhou, China), the mixture was autoclaved for 20 min at $121^{\circ} \mathrm{C}$, 343 cooled, transferred to tubes and centrifuged at $9500 \mathrm{xg}$ for $30 \mathrm{~min}$ at $4{ }^{\circ} \mathrm{C}$. The pellet was recovered and 344 dried at room temperature.

345 PHB quantification was performed by using K-HDBA kit (Megazyme International, Ireland) to detect 346 D-3-hydroxybutyric acid concentration in the samples. The data were reported as PHB \% considered as $347 \mathrm{~g}$ PHB $100 \mathrm{~g}^{-1}$ of weighted samples.

\section{PHAs production fed-batch fermentation experiments}

The fed-batch fermentation experiments were performed in a New Brunswick BioFlo 115 benchtop 351 fermentor (Eppendorf, Milan, Italy) with a working volume of $4 \mathrm{~L}$ employing a pair of 6-blade Rushton impeller. Fermentor was filled with LB medium supplemented with $2 \%(\mathrm{v} / \mathrm{v})$ of $\mathrm{VFA}_{\text {synthetic }}$ or $\mathrm{VFA}_{\text {extracted }}$ and inoculated with 2\% (v/v) C. necator DSM 13513 overnight culture as above reported. The $\mathrm{pH}$ was automatically maintained at 6.5 by adding a solution of $4 \mathrm{M} \mathrm{NaOH}$ setting the deadband for the $\mathrm{pH}$ control at 0.10 . A solution of 3\% (v/v) Antifoam 204 (Sigma-Aldrich, Milan, Italy) was added after $1 \mathrm{~h}$ of 356 fermentation process to break a foam already formed. The experiments were performed at $30{ }^{\circ} \mathrm{C}$ for 48 $357 \mathrm{~h}$ with an agitation speed set to $200 \mathrm{rpm}$ using three different aeration conditions: 1 , air sparging at 1 $358 \mathrm{vvm}$; 2, no aeration; 3 , air sparging at $1 \mathrm{vvm}$ for $12 \mathrm{~h}$ followed by no aeration. $\mathrm{VFA}_{\text {synthetic }}$ or VFA extracted 359 feeding at $2 \%(\mathrm{v} / \mathrm{v})$ was added at $3,6,9$ and $12 \mathrm{~h}$ of the process to improve the maximum accumulation 
360 capability of the culture. Samples were withdrawn at $0,3,6,9,12,24,30$ and $48 \mathrm{~h}$ to measure the optical 361 density (O.D.600nm) and to enumerate bacterial cells (CFU mL $\left.\mathrm{m}^{-1}\right)$. For each sample, a sub-sample was 362 freeze-dried (Lyoquest-55, Telstar) and used for PHB quantification as above reported.

Determination of monomer composition by gas chromatography-mass spectrometry (GC-MS)

365 The PHA monomeric composition was qualitatively analyzed by gas chromatography/mass spectrometry 366 (GC/MS), freeze-dried PHAs extracted were first subjected to methanolysis according to the method of 367 Sathiyanarayanan et al. [50]. In detail, about $8 \mathrm{mg}$ of PHAs was dissolved in $0.8 \mathrm{~mL}$ of chloroform, and 368 then $0.8 \mathrm{~mL}$ of methanol/sulfuric acid $(85: 15 \mathrm{v} / \mathrm{v})$ mixture was added into the vials. After incubation at

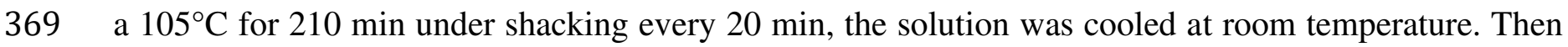
$370 \quad 0.4 \mathrm{~mL}$ of milli-Q water was added and submitted slightly vortexed for $1 \mathrm{~min}$. The samples were centrifuged (Thermofisher scientific, USA) at $9500 \mathrm{xg}$ for $2 \mathrm{~min}$, and $200 \mu \mathrm{L}$ of precipitated organic 372 phase was mixed with crystalline sodium sulphate. $1 \mu \mathrm{l}$ of sample was injected into GC/MS PerkinElmer 373 Autosystem XL (PerkinElmer, USA) Turbomass-Gold PerkinElmer, equipped with a Restek RTX-5MS 374 WCOT, $30 \mathrm{~m} \times 0.25 \mathrm{~mm}$ column. The injector temperature was set at $250{ }^{\circ} \mathrm{C}$, initial isothermal 375 temperature was $40{ }^{\circ} \mathrm{C}$ for $1 \mathrm{~min}$ then increase to $120^{\circ} \mathrm{C}$ at $15^{\circ} \mathrm{C} \mathrm{min}{ }^{-1}$, hold for 2 min, and increase to $300{ }^{\circ} \mathrm{C}$ at $10{ }^{\circ} \mathrm{C} \min ^{-1}$. Helium was used as carrier gas at $1 \mathrm{~mL} \mathrm{~min}^{-1}$. Mass spectra were obtained using electron impact ionization (EI) with energy of $70 \mathrm{eV}$ at a frequency of $0.2 \mathrm{scan} \mathrm{s}^{-1}$ within the $50-600 \mathrm{~m} / \mathrm{z}$ range. Identification of mass signal was carried out by comparing either with standard compounds or molecular libraries such as Nist 05.

\section{NMR characterization}

$3822 \mathrm{mg}$ of freeze-dried PHA were dissolved in $1 \mathrm{~mL}$ of deuterated chloroform (CDCl3) containing $1 \%(\mathrm{v} / \mathrm{v})$ 383 of tetramethylsilane. The mixture was stirred in a vortex, sonicated for 5 minutes, placed at $40{ }^{\circ} \mathrm{C}$ for 15 
minutes to facilitate dissolution and transferred into a stoppered $5 \mathrm{~mm}$ NMR tube. NMR spectra were 385 obtained with a magnet $400 \mathrm{MHz}$ Avance (Bruker Biospin, Rheinstetten, Germany), equipped with a 5 mm Bruker Broadband Inverse (BBI) probe, working at the ${ }^{1} \mathrm{H}$ and ${ }^{13} \mathrm{C}$ frequencies of 400.13 and 100.62 $\mathrm{MHz}$, respectively, and at a temperature of $25 \pm 1{ }^{\circ} \mathrm{C}(298 \pm 1 \mathrm{~K})$. The one-dimensional ${ }^{1} \mathrm{H}$ spectra were acquired with $2 \mathrm{~s}$ of thermal equilibrium delay, a pulse length of $90^{\circ}$ between 7.82 and $7.9 \mu \mathrm{s}(-2 \mathrm{~dB}$ of attenuation), 128 transients, 67584 points in the domain of the time and $16 \mathrm{ppm}(6410.3 \mathrm{~Hz})$ as spectral width. The one-dimensional ${ }^{13} \mathrm{C}$ spectra were acquired by the reverse ${ }^{1} \mathrm{H}_{-}{ }^{13} \mathrm{C}$ decoupling technique. The spectra were acquired with a pulse length of $90^{\circ}$ between 22 and $22.4 \mu$ s, 1200 transients, 32768 points in the domain of the time and $250 \mathrm{ppm}(25125.629 \mathrm{~Hz})$ as spectral width. Spectra were processed by using Bruker TopSpin Software (v. 4.0.2). The free induction decays (FID ${ }_{\mathrm{s}}$ ) were Fourier transformed applying an apodization of $0.3 \mathrm{~Hz}$ for ${ }^{1} \mathrm{H}$ and $1 \mathrm{~Hz}$ for ${ }^{13} \mathrm{C}$ experiments respectively and phase and basic corrections were applied to all spectra.

\section{Formation and characterization of plastic film}

\section{Biopolymer recovery}

Cells of $C$. necator DSM 13513 were recovered by centrifugation (6080 x $g$ for $10 \mathrm{~min}$ ) after $48 \mathrm{~h}$ of 400 incubation at $30{ }^{\circ} \mathrm{C}$ in LB medium supplemented with VFA extracted. Microbial cells were freeze-dried and then suspended in chloroform (40 $\mathrm{mL} \mathrm{CHCl}_{3} \mathrm{~g}^{-1}$ dried cells). After incubation at $37{ }^{\circ} \mathrm{C}$ for $3-5$ days, the 402 solution was filtered (Minisart RC-25, $0.2 \mu \mathrm{m}$, Sartorius Stedim Biotech) to remove all undissolved material, and the filtrate was used to fill glass microplates. Finally, chloroform was evaporated, allowing 404 polymer recovery in the form of a thin bioplastic film [26].

\section{Thermogravimetric Analysis (TGA)}


407 TGA was performed using Thermogravimetric Analyzer, TGA 7/DZ, Perkin Elmer (Japan) equipment. 408 Samples $(3.0 \pm 0.01 \mathrm{mg})$ were placed in aluminum pans inside the thermogravimetric balance and then 409 heated under dry nitrogen atmosphere (gas flow $=20 \mathrm{~mL} / \mathrm{min}$ ) in the range of $25-500{ }^{\circ} \mathrm{C}$ at a heating 410 rate of $10^{\circ} \mathrm{C}$ min. Two characteristic temperatures were collected, corresponding to the onset degradation 411 temperature (To) and to the temperature of the extremum of the first derivate weight versus temperature 412 peak (Tdp), respectively.

413

414 Dynamic vapor sorption analysis (DVS)

415 The absorption isotherms were measured using DVS (dynamic vaporization Q500SA, TA Instrument, 416 New Castle, USA). The main component was a microbalance with an accuracy of $0.1 \mathrm{~g}$. The sample (5 417 to $9 \mathrm{mg}$ ) was placed in an aluminum capsule, an empty aluminum capsule was used as a reference. 418 Measurements were conducted at $40^{\circ} \mathrm{C}$ using the following procedure:

419 1. Conditioning: the samples were conditioned at $0 \% \mathrm{RH}$ for a time necessary to reach a constant 420 weight.

421 2. Absorption: the relative humidity has been increased and brought to $30 \%, 50 \%, 60 \%, 65 \%, 70 \%$, $42275 \%, 80 \%, 85 \%, 90 \%$ and $95 \%$. The sample remained in each step until the constant weight was 423 reached.

424 From the curves relating to the percentage weight increase as a function of time, the absolute humidity 425 (m) was calculated for the equilibrium of each water activity, expressed as milligrams of water 426 absorbed at equilibrium on milligrams of dry substance.

427 Brunauer, Enmett and Teller (BET), (Eq. (1), Guggenheim-Anderson-deBoer (GAB) (Eq. (2), Micha 428 Peleg (Peleg) (Eq. (3), equations were used to describe the experimental data. These models were 429 explained and rearranged as given below: 


$$
X=\frac{x_{m} \text { aw }}{\left.(1-a w)(1+C-1)^{*} a w\right)}
$$

$$
X=\frac{\mathrm{x}_{m} \mathrm{CK} \mathrm{Kaw}_{\mathrm{w}}}{\left(1-K a_{w}\right)\left(1-K a_{w}+C K a_{w}\right)}
$$

434

$$
X=K_{1} a w^{n 1}+K_{2} a w^{n 2}
$$

436

where $\mathrm{X}$ was the equilibrium moisture content $\left(\mathrm{mg} \mathrm{mgd}_{\mathrm{m}}{ }^{-1}\right) ; \mathrm{x}_{\mathrm{m}}$ was the monolayer moisture content (mg 438

$\operatorname{mgd}_{\mathrm{m}}{ }^{-1}$ ); aw was the water activity; $\mathrm{C}$ and $\mathrm{K}$, are GAB constant, $\mathrm{k}_{1}, \mathrm{k}_{2}, \mathrm{n}_{1}$ and $\mathrm{n}_{2}$ are the Peleg model 439 constants.

440 The goodness of fitting of the mathematical models Eqs. (1), (2), (3), were evaluated by means of the 441 root mean squared error (RMSE):

442

443

444

445 446

\section{Statistical analysis}

448 One-way ANOVA followed by Tukey’s HSD post hoc for pairwise comparison of means $($ at $\mathrm{P}<0.05)$ 449 was used to assess the difference in the PHB percentage. Statistical analyses were performed using SPSS 45021.0 statistical software package (SPSS Inc., Cary, NC, USA).

$$
\mathrm{RMSE}=\sqrt{\frac{\Sigma\left(\mathrm{M}_{\mathrm{e}}-M p\right)^{2}}{n}}
$$

Abbreviations

453 PHAs: polyhydroxyalkanoates; VFAs: volatile fatty acids; PHB: polyhydroxybutyrate; SCL: short454 chain-length; $\mathrm{P}(3 \mathrm{HB})$ : poly(3-hydroxybutyrate); $\mathrm{P}(3 \mathrm{HV})$ : poly(3-hydroxyvalerate); $\mathrm{P}(4 \mathrm{HB})$ : poly(4- 
455 hydroxybutyrate); P(3HB-co-3HV): poly(3-hydroxybutyrate-co-3-hydroxyvalerate); GC-MS: Gas 456 Chromatography-Mass Spectrometry; NMR: Nuclear Magnetic Resonance; PP: polypropylene; PE:

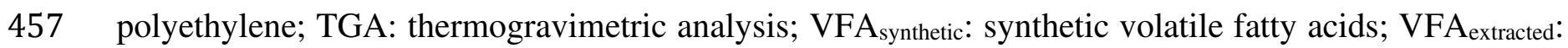
458 extracted volatile fatty acids; HPLC: high-performance liquid chromatography; DVS: dynamic vapor 459 sorption analysis; RMSE: root mean squared error; GAB: Guggenheim-Anderson-deBoer; BET: 460 Brunauer, Enmett and Teller; Peleg: Micha Peleg.

461

462 Declarations

463 Ethics approval and consent to participate

464 Not applicable

465

466 Consent for publication

467 Not applicable

468

469 Availability of data and material

470 Not applicable

471

472 Competing interests

473 The authors declare that they have no competing interests.

474

$475 \quad$ Funding

476 Not applicable.

477

478 Author contributions 
479 GP and WG performed microbiological experiments, analyzed data and drafted the manuscript. ET and 480 FAG performed TGA and DVS analyses and drafted the manuscript for this part. AP and SC performed 481 GC-MS and NMR analyses and drafted the manuscript for this part. AR performed fed-batch 482 fermentation experiments. VF revised the manuscript. OP conceived the study, participated in its design 483 and revised the manuscript. VV contributed to coordinate the study and revised the manuscript.

484

485 Acknowledgements

486 Not applicable

487

488

References

489 1. Guillard V, Gaucel S, Fornaciari C, Angellier-Coussy, H, Buche P, Gontard N. The next generation 490 of sustainable food packaging to preserve our environment in a circular economy context. Front. $491 \quad$ Nutr. 2018;5:121.

492 2. Urtuvia V, Villegas P, González M, Seeger M. Bacterial production of the biodegradable plastics 493 polyhydroxyalkanoates. Int. J. Biol. Macromol. 2014;70:208-213.

494 3. Pepe O. Microbial solutions to recover waste through a regenerative approach. EC Microbiology. $495 \quad 2018 ; 14: 778-779$.

496 4. Pagliano G, Ventorino V, Panico A, Pepe O. Integrated systems for biopolymers and bioenergy 497 production from organic waste and by-products: a review of microbial processes. Biotechnol. $498 \quad$ Biofuels. 2017;10:113.

499 5. Wang K, Yin J, Shen D, Li N. Anaerobic digestion of food waste for volatile fatty acids (VFAs) 500 production with different types of inoculum: Effect of pH. Bioresour. Technol. 2014;161:395-401. 
501 6. Pagliano G, Ventorino V, Panico A, Romano I, Robertiello A, Pirozzi F, Pepe O. The effect of 502 bacterial and archaeal populations on anaerobic process fed with mozzarella cheese whey and 503 buttermilk. J. Environ. Manage. 2018;217:110-122.

504 7. Chen Y, Luo J, Yan Y, Feng L. Enhanced production of short-chain fatty acid by co-fermentation 505 of waste activated sludge and kitchen waste under alkaline conditions and its application to microbial 506 fuel cells. Appl. Energy. 2013;102:1197-1204.

507 8. Oliveira C, Silva C, Carvalho G, Reis M. Strategies for efficiently selecting PHA producing mixed 508 microbial cultures using complex feedstocks: Feast and famine regime and uncoupled carbon and 509 nitrogen availabilities. New Biotechnol. 2017;37:69-79.

510 9. Kumar G, Ponnusamy V, Bhosale R, Shobana S, Yoon J, Bhatia S, Rajesh Banu J, Kim S. A review 511 on the conversion of volatile fatty acids to polyhydroxyalkanoates using dark fermentative effluents 512 from hydrogen production. Bioresour. Technol. 2019;287:121427.

513 10. Ghimire A, Frunzo L, Pirozzi F, Trably E, Escudie R, Lens P, Esposito G. A review on dark 514 fermentative biohydrogen production from organic biomass: Process parameters and use of by515 products. Appl. Energy. 2015;144:73-95.

516 11. Pagliano G, Ventorino V, Panico A, Romano I, Pirozzi F, Pepe O. Anaerobic process for bioenergy 517 recovery from dairy waste: meta-analysis and enumeration of microbial community related to 518 intermediates production. Front. Microbiol. 2019;9:3229.

519 12. Vandamme P. Taxonomy of the genus Cupriavidus: a tale of lost and found. Int. J. Syst. Evol. $520 \quad$ Microbiol. 2004;54:2285-2289.

521 13. Keshavarz T, Roy I. Polyhydroxyalkanoates: bioplastics with a green agenda. Curr. Opin. Microbiol. $522 \quad 2010 ; 13: 321-326$.

523 14. Liong MT. Beneficial microorganisms in agriculture, aquaculture and other areas. Switzerland: $524 \quad$ Springer International Publishers; 2015. 
525 15. Muhr A, Rechberger E, Salerno A, Reiterer A, Malli K, Strohmeier K, Schober S, Mittelbach M, 526 Koller M. Novel Description of mcl-PHA biosynthesis by Pseudomonas chlororaphis from animal527 derived waste. J. Biotechnol. 2013;165:45-51.

528 16. Grassie N, Murray EJ, Holmes PA. The thermal degradation of poly(-(d)- $\beta$-hydroxybutyric acid): 529 Part 1-Identification and quantitative analysis of products. Polym. Degrad. Stab. 1984;6:47-61.

530 17. Yeo J, Muiruri J, Thitsartarn W, Li Z, He C. Recent advances in the development of biodegradable 531 PHB-based toughening materials: Approaches, advantages and applications. Mater. Sci. Eng. C. $532 \quad 2018 ; 92: 1092-1116$.

533 18. Morikawa H, Marchessault RH. Pyrolysis of bacterial polyalkanoates. Can. J. Chem. 2006;59:23062313.

535 19. Kawalec M, Kurcok P, Kowalczuk M, Foltran I, Adamus G, Kurcok P, Scandola M. Carboxylate536 induced degradation of poly(3-hydroxybutyrate). Biomacromolecules 2007;8:2-7.

537 20. Koller M, Maršalek L, Miranda de Sousa Dias M, Brainegg G. Producing microbial 538 polyhydroxyalkanoate (PHA) biopolyesters in a sustainable manner. New Biotechnol. 2017;37:2453938.

540 21. Obruca S, Marova I, Stankova M, Mravcova L, Svoboda Z. Effect of ethanol and hydrogen peroxide 541 on poly(3-hydroxybutyrate) biosynthetic pathway in Cupriavidus necator H16. World J. Microbiol. $542 \quad$ Biotechnol. 2010;26:1261-1267.

543 22. Jaremko M, Yu J. The initial metabolic conversion of levulinic acid in Cupriavidus necator. J. $544 \quad$ Biotechnol. 2011;155:293-298.

545 23. Kalia VC, Raizaida N, Sonakya V. Bioplastics. J. Sci. Ind. Res. 2000;59:433-445.

546 24. Yun JH, Sawant SS, Kim BS. Production of polyhydroxyalkanoates by Ralstonia eutropha from 547 volatile fatty acids. Korean J. Chem. Eng. 2013;30:2223-2227. 

Starch based polyhydroxybutyrate production in engineered Escherichia coli. Bioprocess Biosyst. Eng. 2015;38:1479-1484.

26. Duque A, Oliveira C, Carmo I, Gouveia A, Pardelha F, Ramos A, Reis M. Response of a three-stage process for PHA production by mixed microbial cultures to feedstock shift: impact on polymer composition. New Biotechnol. 2014;31:276-288.

554 27. Beccari M, Dionisi D, Giuliani A, Majone M, Ramadori R. Effect of different carbon sources on 555 aerobic storage by activated sludge. Water Sci. Technol. 2002;45:157-168.

556 28. Jackson F, Dawes E. Regulation of the tricarboxylic acid cycle and poly-hydroxybutyrate 557 metabolism in Azotobacter beijerinckii grown under nitrogen or oxygen limitation. J. Gen. Microbiol. $558 \quad 1976 ; 97: 303-312$.

559 29. De Almeida A, Giordano A, Nikel P, Pettinari M. Effects of aeration on the synthesis of poly(3560 hydroxybutyrate) from glycerol and glucose in recombinant Escherichia coli. Appl. Environ. $561 \quad$ Microbiol. 2010;76:2036-2040.

562 30. Nath A, Dixit M, Bandiya A, Chavda S, Desai AJ. Enhanced PHB production and scale up studies 563 using cheese whey in fed batch culture of Methylobacterium sp. ZP24. Bioresour. Technol. $564 \quad 2008 ; 99: 5749-5755$.

565 31. Nikel PI, Pettinari MJ, Galvagno MA, Mèndez BS. Poly(3-hydroxybutyrate) synthesis by 566 recombinant Escherichia coli arcA mutants in microaerobiosis. Appl. Environ. Microbiol. $567 \quad 2006 ; 72: 614-2620$.

568 32. Cavalheiro JMBT, De Almeida MCMD, Grandfils C, Da Fonseca MMR. Poly(3-hydroxybutyrate) 569 production by Cupriavidus necator using waste glycerol. Process Biochem. 2009;44:509-515. 
33. Kim G, Lee I, Yoon S, Shin Y, Park Y. Enhanced yield and a high production of medium-chainlength poly(3-hydroxyalkanoates) in a two-step fed-batch cultivation of Pseudomonas putida by combined use of glucose and octanoate. Enzyme Microb. Technol. 1997;20:500-505.

573 34. Borah B, Thakur PS, Nigam JN. The influence of nutritional and environmental conditions on the 574 accumulation of poly-ß-hydroxybutyrate in Bacillus mycoides RLJ B-017. J. Appl. Microbiol. 2002;92:776-783.

35. Passanha P, Esteves S, Kedia G, Dinsdale R, Guwy A. Increasing polyhydroxyalkanoate (PHA) yields from Cupriavidus necator by using filtered digestate liquors. Bioresour. Technol. 2013;147:345-352.

36. Da Cruz Pradella J, Ienczak J, Delgado C, Taciro M. Carbon source pulsed feeding to attain high yield and high productivity in poly(3-hydroxybutyrate) (PHB) production from soybean oil using Cupriavidus necator. Biotechnol. Lett. 2012;34:1003-1007.

37. Yu J, Si Y, Keung W, Wong W. Kinetics modeling of inhibition and utilization of mixed volatile fatty acids in the formation of polyhydroxyalkanoates by Ralstonia eutropha. Process Biochem. 2002;37:731-738.

38. Li SD, He JD, Yu PH, Cheung MK. Thermal degradation of poly(3-hydroxybutyrate) and poly(3hydroxybutyrate-co-3-hydroxyvalerate) as studied by TG, TG-FTIR, and Py-GC/MS. J. Appl. Polym. Sci. 2003;89:1530-1536.

39. Bordes P, Pollet E, Bourbigot S, Avérous L. Structure and properties of PHA/clay nanobiocomposites prepared by melt intercalation. Macromol. Chem. Phys. 2008;209:1474-1484.

40. Herrera-Kao WA, Loría-Bastarrachea MI, Pérez-Padilla Y, Cauich-Rodríguez JV, Vázquez-Torres H, Cervantes-Uc JM. Thermal degradation of poly(caprolactone), poly(lactic acid), and poly(hydroxybutyrate) studied by TGA/FTIR and other analytical techniques. Polym. Bull. 2018;75:4191-4205. 
594 41. Xiang H, Wen X, Miu X, Li Y, Zhou Z, Zhu M. Thermal depolymerization mechanisms of poly(3595 hydroxybutyrate-co-3-hydroxyvalerate). Prog. Nat. Sci. 2016;26:58-64.

596 42. Follain N, Belbekhouche S, Bras J, Siqueira G, Marais S, Dufresne A. Water transport properties of 597 bio-nanocomposites reinforced by Luffa cylindrica cellulose nanocrystals. J. Membr. Sci. 598 $2013 ; 427: 218-229$.

43. Follain N, Chappey C, Dargent E, Chivrac F, Crétois R, Marais S. Structure and barrier properties 600 of biodegradable polyhydroxyalkanoate films. J. Phys. Chem. C. 2014;118:6165-6177.

44. Tenn N, Follain N, Soulestin J, Crétois R, Bourbigot S, Marais S. Effect of nanoclay hydration on 603 barrier properties of PLA/montmorillonite based nanocomposites. J. Phys. Chem. C.

45. Peleg M. Assessment of a semi-empirical four parameters general model for sigmoid moisture 2013;117:12117-12135.

46. Yoshida CMP, Maciel VBV, Mendonça MED, Franco TT. Chitosan biobased and intelligent films: Monitoring pH variations. LWT Food Sci. Technol. 2014;55:83-89.

47. Turhan M, Sayar S, Gunasekaran S. Application of Peleg model to study water absorption in 609

48. Ostle A, Holt J. Nile blue A as a fluorescent stain for poly-beta-hydroxybutyrate. Appl. Environ.

49. Strazzullo G, Gambacorta A, Vella FM, Immirzi B, Romano I, Calandrelli V, Lama L. ChemicalMicrobiol. 1982;44:238-241. physical characterization of polyhydroxyalkanoates recovered by means of a simplified method from cultures of Halomonas campaniensis. World J. Microbiol. Biotechnol. 2008;24:1513-1519.

50. Sathiyanarayanan G, Kant Bhatia S, Song HS, Jeon JM, Kim J, Lee YK, Kim YG, Yang YH. Production and characterization of medium-chain-length polyhydroxyalkanoate copolymer from Arctic psychrotrophic bacterium Pseudomonas sp. Int. J. Biol. Macromol. 2017;97:710-720. 
620 Figure 1. Microbial growth of Cupriavidus necator strains in LB medium supplemented with VFA 621 (a), VFA extracted mixture (b) and LB medium (c, control) during $72 \mathrm{~h}$ of incubation at $30{ }^{\circ} \mathrm{C}$. 622

623 Figure 2. PHB production (\%) and microbial counts (log CFU mL $\left.{ }^{-1}\right)$ of $C$. necator DSM 13513 in batch 624 cultures grown in LB medium supplemented with VFA synthetic $_{\text {(a), VFA }}$ extracted mixture (b) and LB medium 625 (c, control) during $48 \mathrm{~h}$ of incubation at $30{ }^{\circ} \mathrm{C}$.

626

627 Figure 3. PHAs accumulation in C. necator DSM 13513 cells grown in LB medium supplemented with 628 VFA $_{\text {synthetic }}(\mathrm{a} ; 24 \mathrm{~h})$ or VFA extracted mixture (b) observed by fluorescence microscope (Axiovert 200M, 629 Zeiss, Göttingen, Germany) after $48 \mathrm{~h}$ of incubation at $30^{\circ} \mathrm{C}$, corresponding to the maximum production 630 in the experimental conditions.

631

632 Figure 4. GC-MS total-ion chromatogram and spectrum of PHA monomers recovered by C. necator 633 DSM 13513 grown with $\operatorname{VFA}_{\text {synthetic }}(\mathrm{a})$, and VFA extracted mixture (b).

634

635 Figure 5. ${ }^{1} \mathrm{H}$ NMR (a) and ${ }^{13} \mathrm{C}$ NMR (b) proton spectrum of PHA from substrates with $\mathrm{VFA}_{\text {synthetic }}(\mathrm{A})$, 636 VFA extracted mixture (B) and standard Poly (R) -3-hydroxybutyric acid.

637

638 Figure 6. Bioplastic disk obtained from the microbial cells of C. necator DSM 13513 grown with 639 VFA $_{\text {extracted }}$ mixture from digested dairy wastes effluent. 
641 Figure 7. Thermogravimetric (TGA) and dynamic vapor sorption (DTG) analysis of PHA films at a 642 heating rate of $10^{\circ} \mathrm{C} / \mathrm{min}$.

643

644 Figure 8. Equilibrium moisture sorption (black circle) and desorption (grey circle) isotherm of PHA.

645 Line represent the fitting of the Guggenheim-Anderson-deBoer (GAB) model to the experimental data 646 of sorption isotherm.

647 
648 Table 1. Maximum PHB (\%) accumulated by C. necator DSM13513 grown in LB supplemented with 649 mixture of $\mathrm{VFA}_{\text {synthetic }}, \mathrm{VFA}_{\text {extracted }}$ in different cultivation conditions.

\begin{tabular}{|c|c|c|c|c|}
\hline \multirow[t]{2}{*}{ Operating mode } & \multicolumn{2}{|c|}{$\begin{array}{l}\text { Carbon source and } \\
\text { aeration conditions }\end{array}$} & \multirow{2}{*}{$\begin{array}{c}\begin{array}{c}\text { PHB } \\
(\%)\end{array} \\
0.31 \pm 0.001^{\mathrm{E}}\end{array}$} & \multirow{2}{*}{$\begin{array}{c}\text { Time } \\
\text { (h) }\end{array}$} \\
\hline & VFA $_{\text {synthetic }}$ & under shaken & & \\
\hline \multirow[t]{3}{*}{ *Batch culture } & $\mathrm{VFA}_{\text {extracted }}$ & under shaken & $0.48 \pm 0.006^{\mathrm{D}}$ & 48 \\
\hline & without VFA & under shaken & $0.025 \pm 0.002^{\mathrm{F}}$ & 24 \\
\hline & & no aeration & $0.81 \pm 0.07^{\mathrm{B}}$ & 48 \\
\hline \multirow{3}{*}{$\begin{array}{l}\text { §Fed-batch } \\
\text { fermentation }\end{array}$} & $\mathrm{VFA}_{\text {synthetic }}$ & aeration & $0.60 \pm 0.01^{\mathrm{C}}$ & 48 \\
\hline & & $12 \mathrm{~h}$ of aeration & $1.34 \pm 0.02^{\mathrm{A}}$ & 48 \\
\hline & $\mathrm{VFA}_{\text {extracted }}$ & $12 \mathrm{~h}$ of aeration & $0.52 \pm 0.03^{\mathrm{CD}}$ & 48 \\
\hline
\end{tabular}

650

651

652

653

654

655

656

657

658
*LB medium $(600 \mathrm{~mL})$ with $2 \%(\mathrm{v} / \mathrm{v})$ of $\mathrm{VFA}_{\text {synthetic, }} \mathrm{VFA}_{\text {extracted }}$ or without VFA (control). Incubation at $30{ }^{\circ} \mathrm{C}$ for $48 \mathrm{~h}$ under shaken at $200 \mathrm{rpm}$.

${ }^{\S} \mathrm{LB}$ medium (4 L) with $2 \%(\mathrm{v} / \mathrm{v})$ of $\mathrm{VFA}_{\text {synthetic }}$ or $\mathrm{VFA}_{\text {extracted. }} \mathrm{pH}$ at 6.5 . Incubation at $30{ }^{\circ} \mathrm{C}$ for $48 \mathrm{~h}$ with agitation speed set at $200 \mathrm{rpm}$. Feeding at 2\% (v/v) added at 3, 6, 9 and $12 \mathrm{~h}$. Aeration: air sparging at $1 \mathrm{vvm;} 12 \mathrm{~h}$ of aeration: air sparging at $1 \mathrm{vvm}$ for $12 \mathrm{~h}$ followed by no aeration; no aeration.

The values represent the means \pm SD of three replicates. Different letters indicate significant differences $(\mathrm{P}<0.05)$. 
659

660

661

662
Table 2. BET, GAB and Peleg parameters obtained from isotherms of PHA film at $40^{\circ} \mathrm{C}$.

\begin{tabular}{cll}
\hline Model & \multicolumn{1}{c}{$\begin{array}{c}\text { Model } \\
\text { parameters }\end{array}$} & Value \\
\hline BET & $\mathrm{m}_{0}$ & 0.022 \\
& $\mathrm{C}$ & 0.723 \\
& $\mathrm{RMSE}$ & 0.0001 \\
& $\mathrm{R}^{2}(\%)$ & 97.63 \\
$\mathrm{GAB}$ & $\mathrm{xm}\left(\mathrm{g} \mathrm{g}_{\mathrm{dm}}{ }^{-1} \%\right)$ & 0.052 \\
& $\mathrm{C}$ & 0.003 \\
& $\mathrm{~K}$ & 0.791 \\
& $\mathrm{RMSE}$ & 0.0036 \\
& $\mathrm{R}^{2}(\%)$ & 99.7 \\
& & \\
Peleg & $\mathrm{k}_{1}\left(\mathrm{~g} \mathrm{~g}_{\mathrm{dm}}{ }^{-1} \% \mathrm{~h}^{-1}\right)$ & 0.087 \\
& $\mathrm{k}_{2}$ & 0.214 \\
& $\mathrm{n}_{1}$ & 2.176 \\
& $\mathrm{n}_{2}$ & 14.929 \\
& $\mathrm{RMSE}^{2}$ & 0.0010 \\
& $\mathrm{R}^{2}(\%)$ & 99.97 \\
\hline
\end{tabular}


Figures
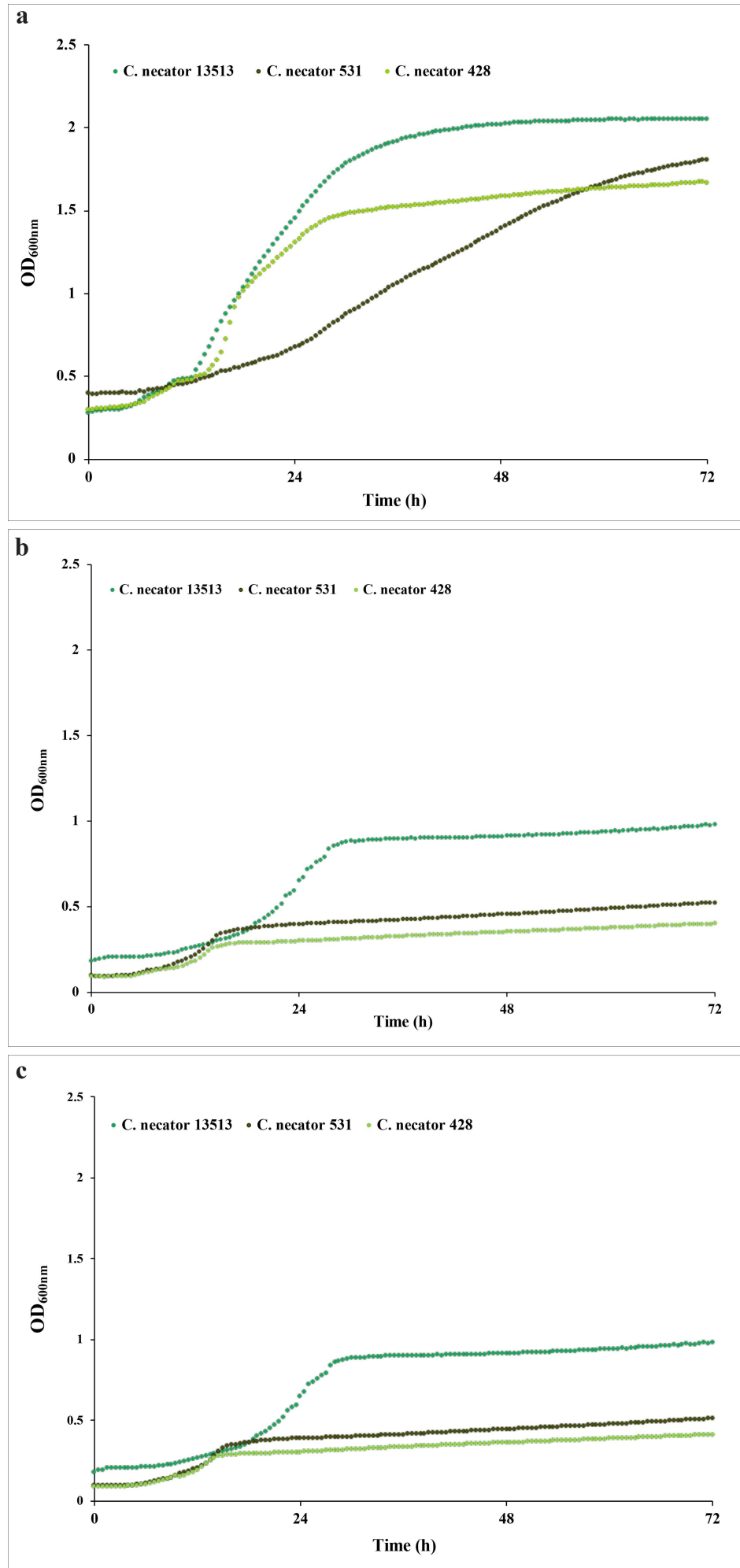

\section{Figure 1}

Microbial growth of Cupriavidus necator strains in LB medium supplemented with VFAsynthetic (a), VFAextracted mixture (b) and LB medium (c, control) during $72 \mathrm{~h}$ of incubation at $30^{\circ} \mathrm{C}$. 

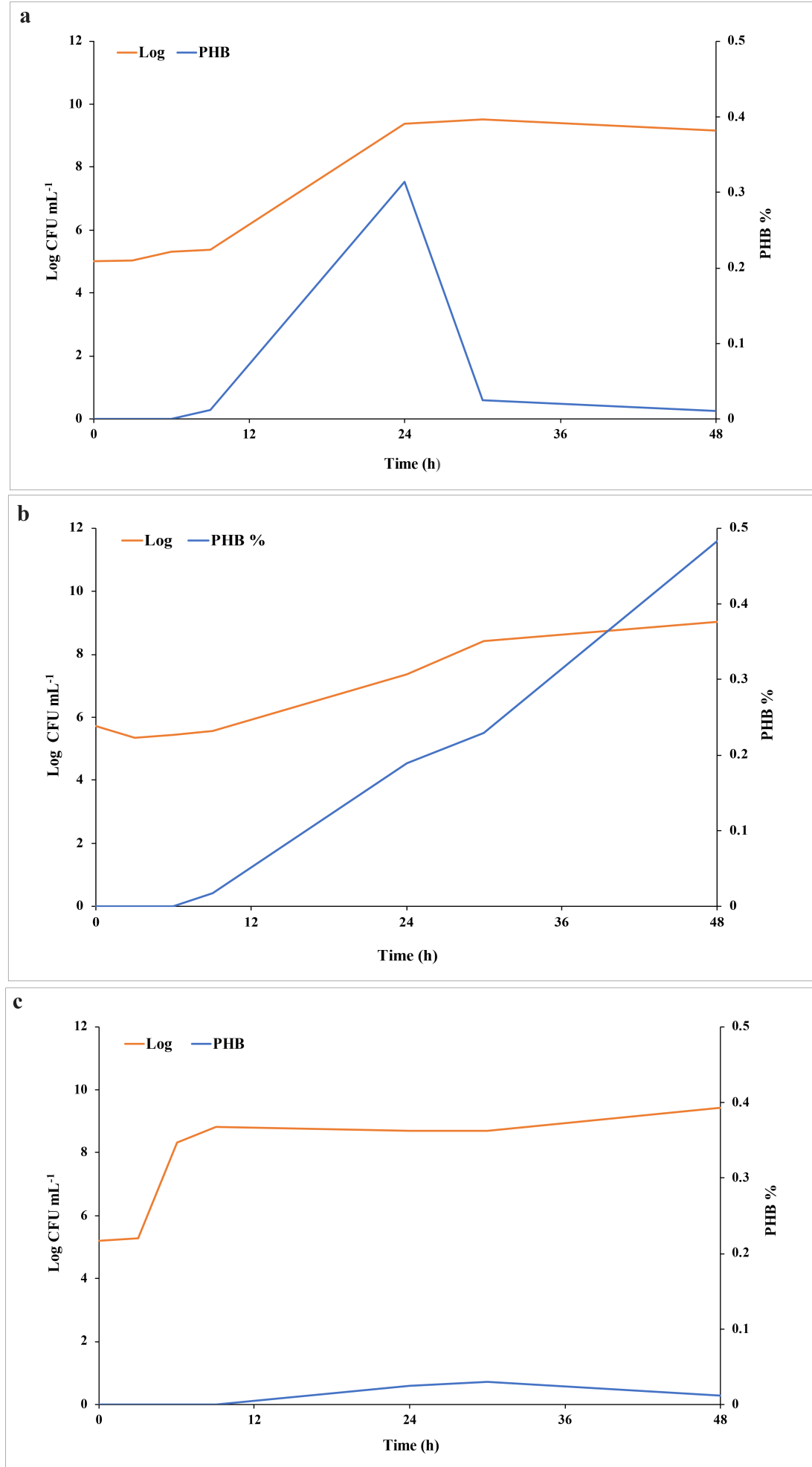

\section{Figure 2}

PHB production (\%) and microbial counts (log CFU mL-1) of C. necator DSM 13513 in batch cultures grown in LB medium supplemented with VFAsynthetic (a), VFAextracted mixture (b) and LB medium (c, control) during $48 \mathrm{~h}$ of incubation at $30^{\circ} \mathrm{C}$. 

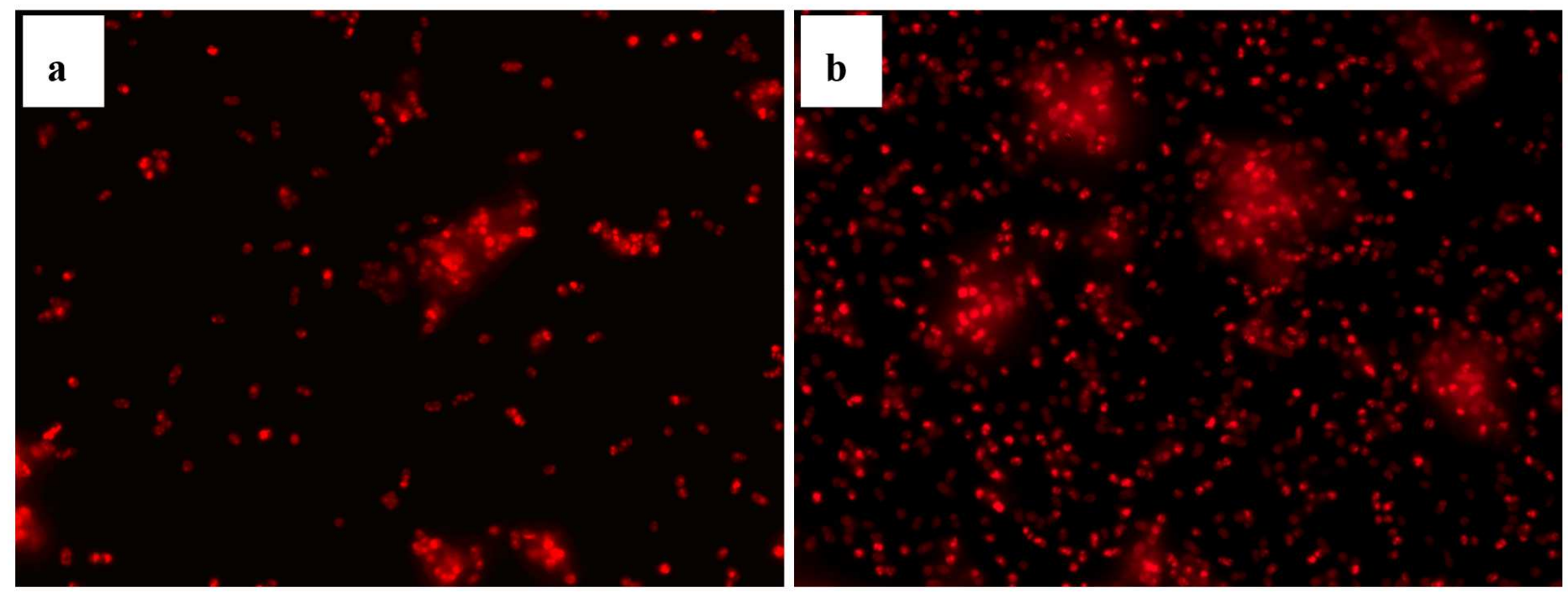

\section{Figure 3}

PHAs accumulation in C. necator DSM 13513 cells grown in LB medium supplemented with VFAsynthetic (a; 24h) or VFAextracted mixture (b) observed by fluorescence microscope (Axiovert 200M, Zeiss, Göttingen, Germany) after $48 \mathrm{~h}$ of incubation at $30^{\circ} \mathrm{C}$, corresponding to the maximum production in the experimental conditions. 

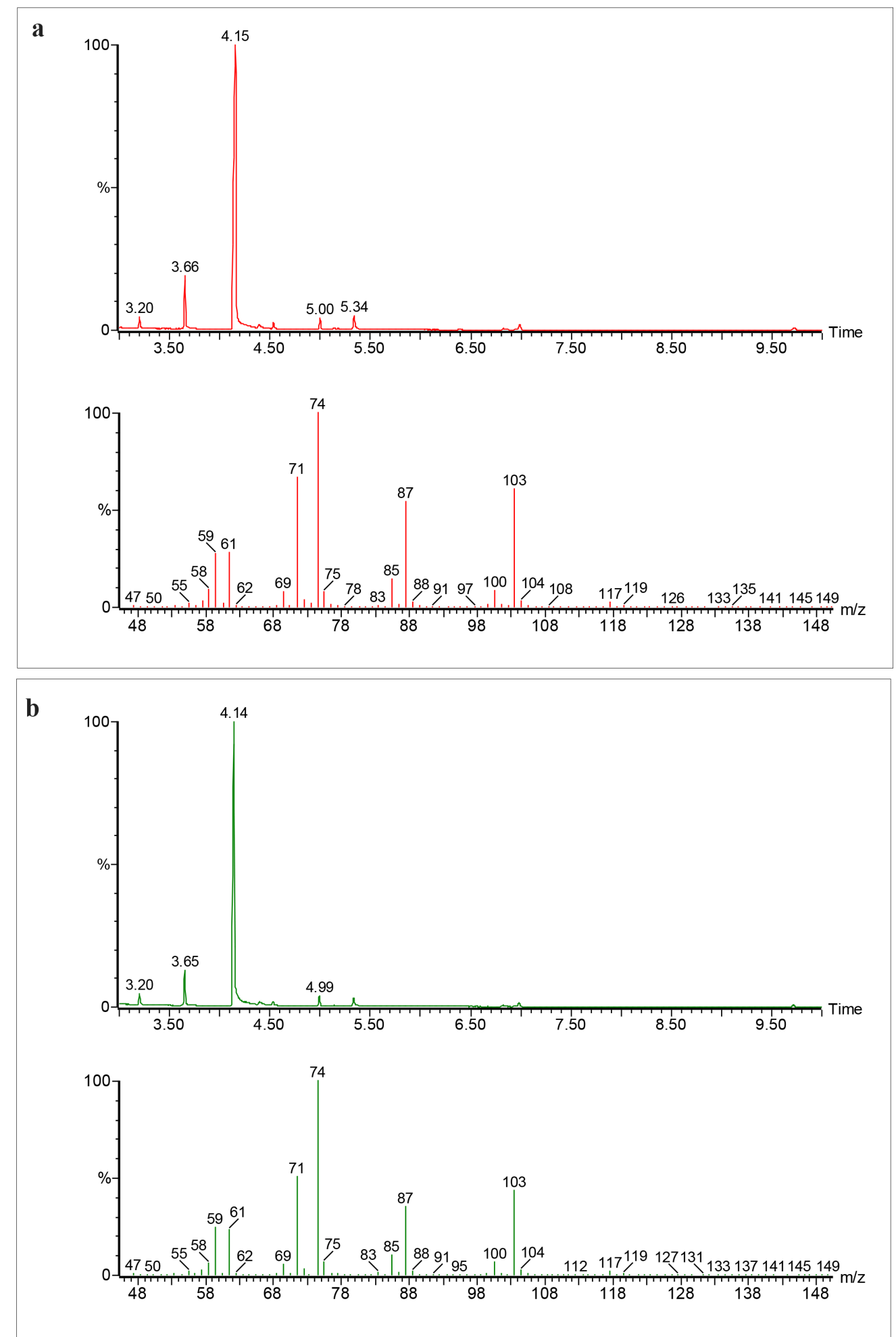

\section{Figure 4}

GC-MS total-ion chromatogram and spectrum of PHA monomers recovered by C. necator DSM 13513 grown with VFAsynthetic (a), and VFAextracted mixture (b). 
a

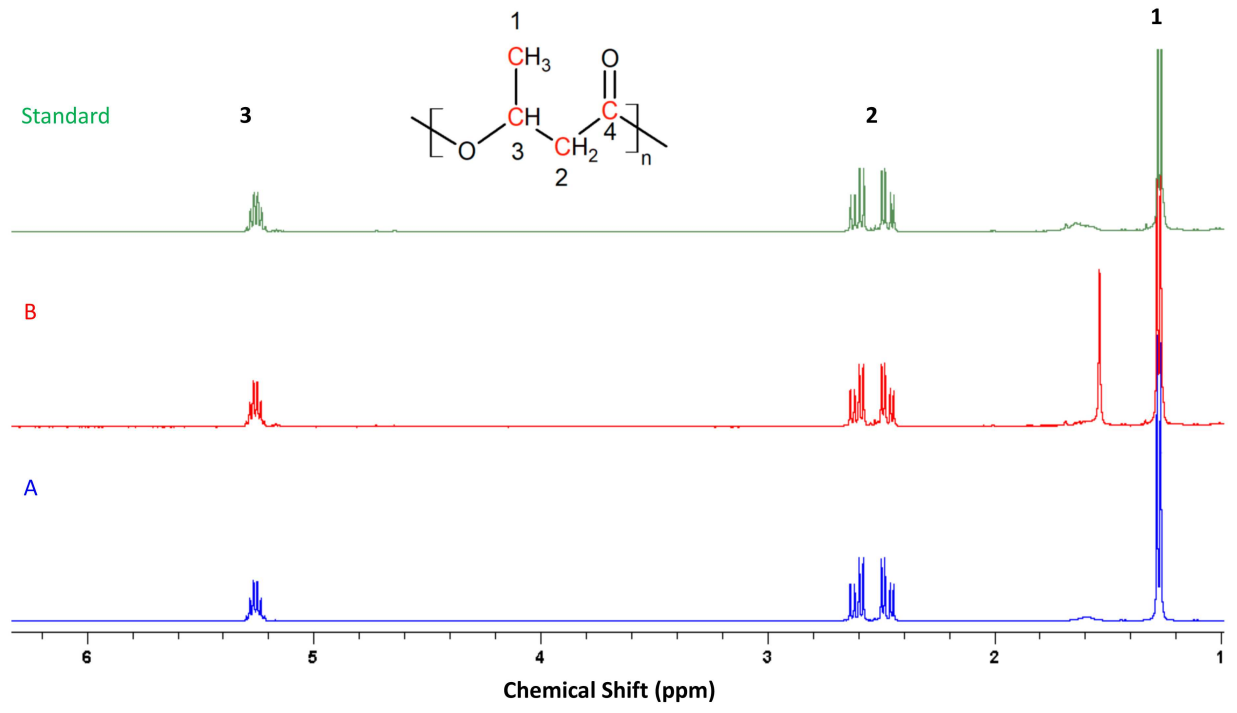

b

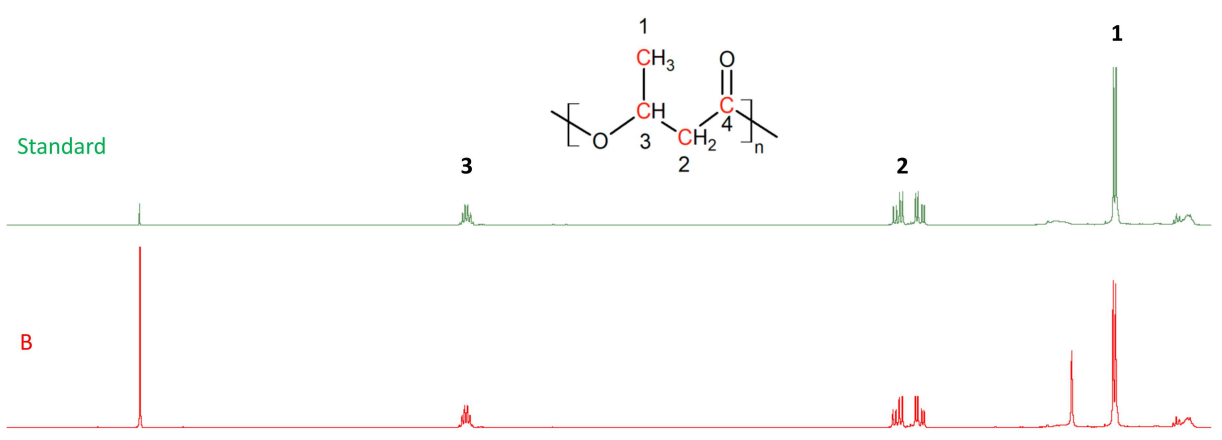

A

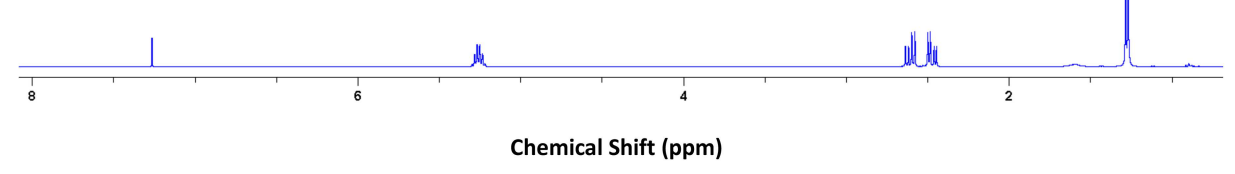

Chemical Shift (ppm)

Figure 5

H NMR (a) and 13C NMR (b) proton spectrum of PHA from substrates with VFAsynthetic (A), VFAextracted mixture (B) and standard Poly (R) -3-hydroxybutyric acid. 

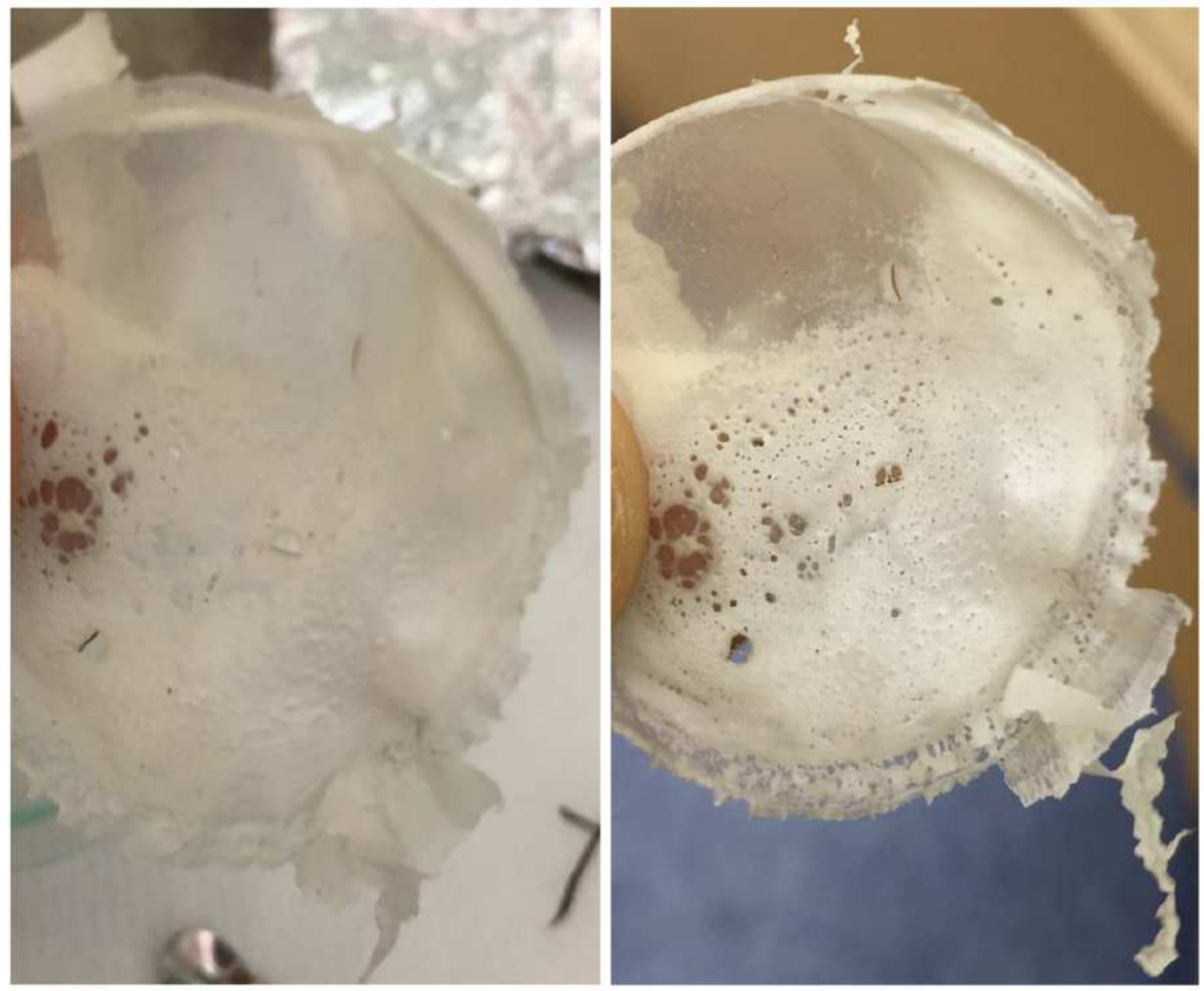

Figure 6

Bioplastic disk obtained from the microbial cells of C. necator DSM 13513 grown with VFAextracted mixture from digested dairy wastes effluent. 


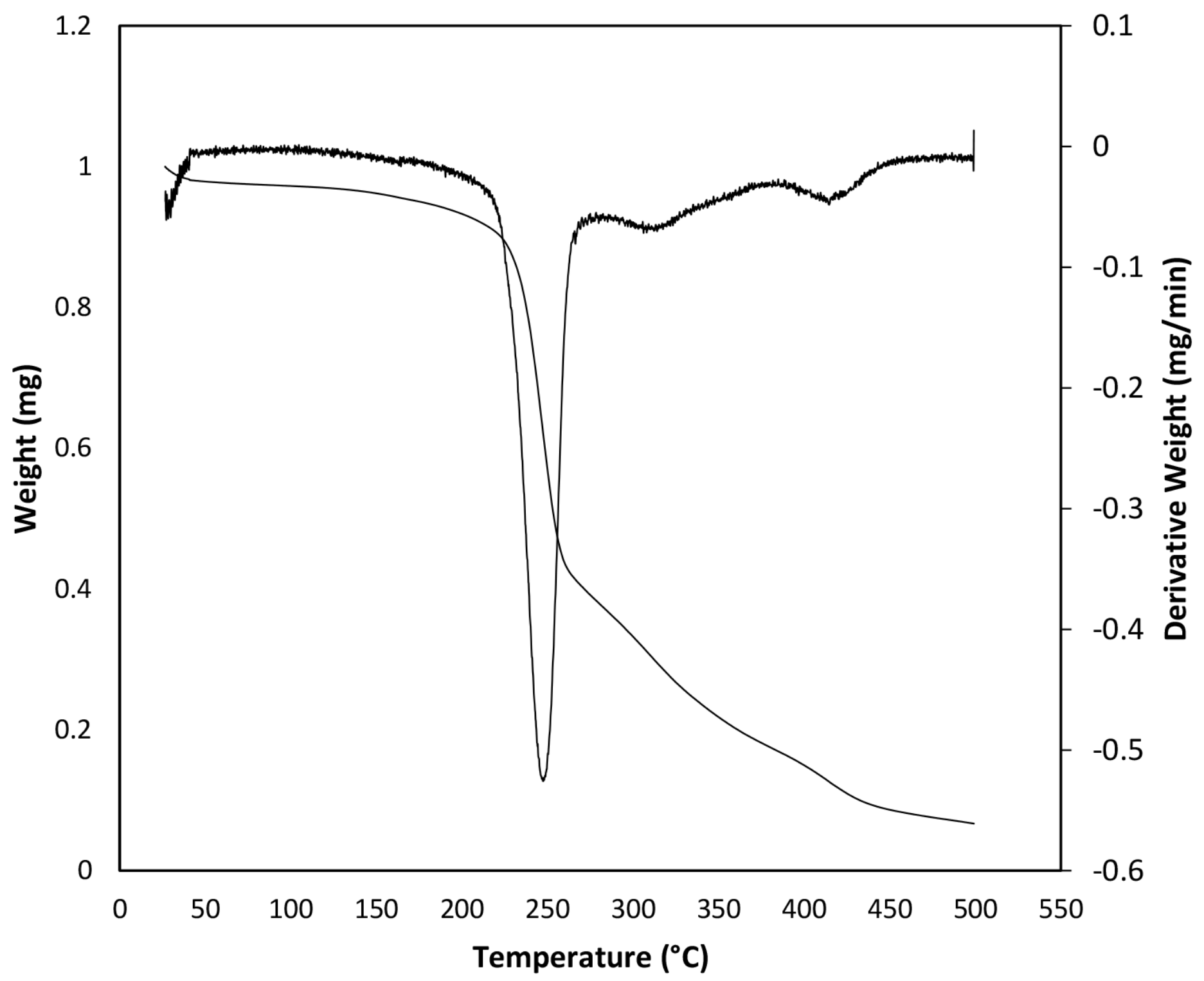

Figure 7

Thermogravimetric (TGA) and dynamic vapor sorption (DTG) analysis of PHA films at a heating rate of $10^{\circ} \mathrm{C} / \mathrm{min}$. 


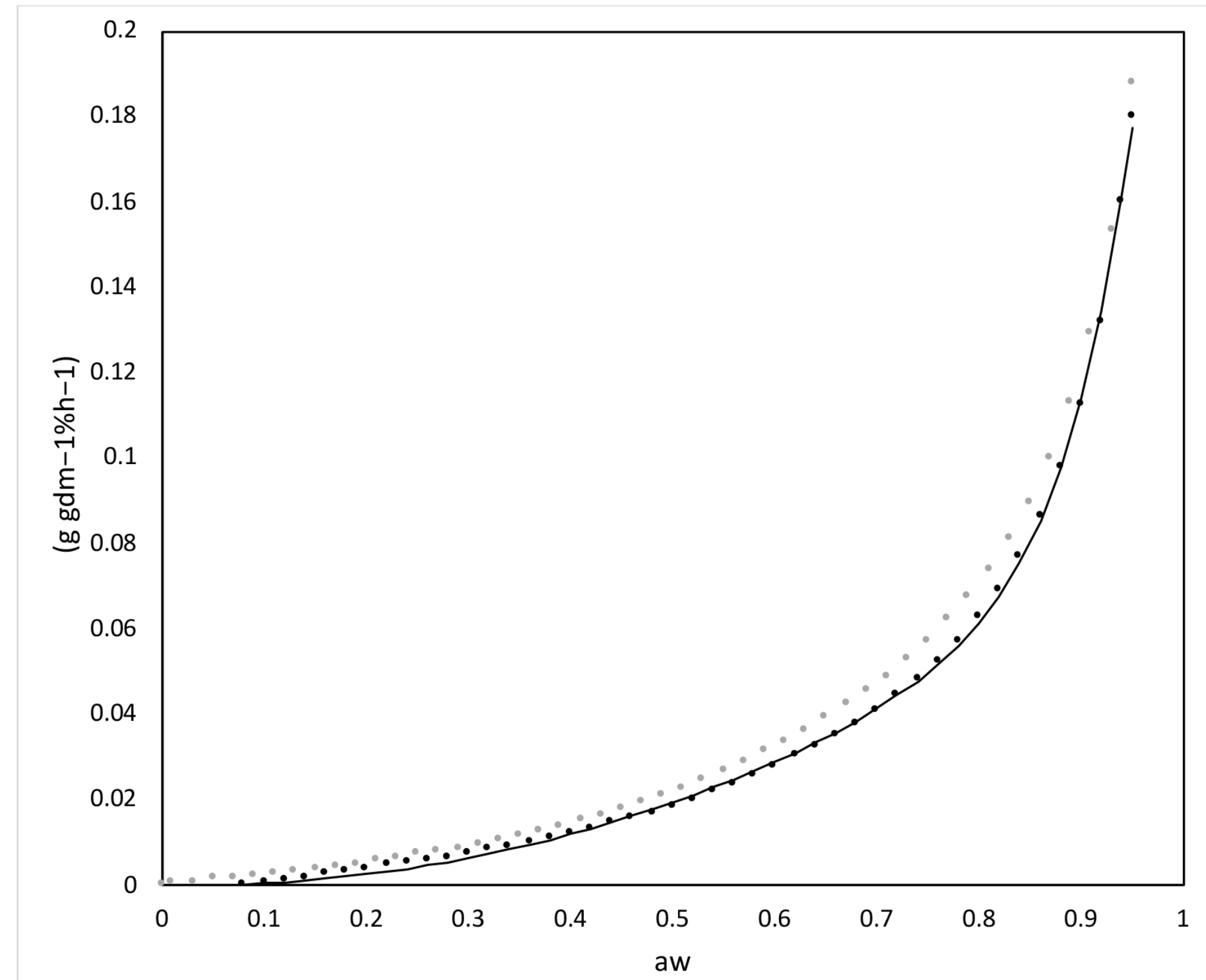

Figure 8

Equilibrium moisture sorption (black circle) and desorption (grey circle) isotherm of PHA. Line represent the fitting of the Guggenheim-Anderson-deBoer (GAB) model to the experimental data of sorption isotherm. 